\title{
SIDE EFFECTS OF LONG - TERM GLUCOCORTICOID THERAPY: CASE REPORT
}

\author{
IOANA-CODRUȚA LEBĂDĂ $\breve{1}^{1}$ ELENA TEODORA MĂEREAN ${ }^{2}$, ROXANA-FLORINA INȚA $\breve{~}^{3}$ \\ 1,3 “Lucian Blaga" University of Sibiu, ${ }^{2}$ Sibiu County Emergency Clinical Hospital
}

Keywords: medication, glucocorticoids, osteoporosis, insufficiency self- Abstract: Glucocorticoids are one of the most common classes of drugs used to treat a diverse variety of inflammatory and autoimmune disorders. Despite their effects, long-term therapy exposes patients to multiple side effects, such as weight gain, high blood pressure, adrenal insufficiency, osteoporosis adrenal and a high risk of infections. We present the case of a 61-year-old female with osteoporosis secondary to glucocorticoid therapy, adrenal insufficiency, new-onset diabetes mellitus and mixed dyslipidemia, manifestations that occurred as a result of self-administration of Medrol for one year. The patient presented to the hospital for thoracic back pain, being sent to the endocrinologist due to radiological changes suggestive of vertebral compressions.

\section{INTRODUCTION}

The term of glucocorticoids refers to a group of biochemical agents- hormones- that are produced by the human body. The synthesis of these hormones takes place in the adrenal cortex (zona fasciculate), starting from cholesterol and involves several enzymatically mediated reactions.(1)

The main agent of this class is cortisol, a hormone that plays an important role in physiological processes such as metabolism, the normal function of the cardiovascular system, mediating immune and stress reactions. The regulation of cortisol secretion is done through the HPA (hypothalamicpituitary- adrenal) axis.(2)

Thus, CRH secreted by the hypothalamus causes the release of ACTH from the anterior pituitary gland, which will act on the adrenal glands in order to stimulate cortisol secretion. Consecutively cortisol has a negative feedback, regarding the release of ACTH and CRH.(1,2)

Exogenous glucocorticoids are pharmacological agents used to treat a diverse variety of chronic and autoimmune inflammatory conditions like respiratory diseases, rheumatological, hematological, neurological, digestive, eye or skin disorders.(3)

Despite their beneficial effects on these ailments, long-term glucocorticoid therapy exposes patients to multiple side effects, the most common being weight gain, high blood pressure, hyperglycemia and diabetes, hyperlipidemia, as well as peptic ulcer disease, adrenal suppression, osteoporosis, high intraocular pressure, myopathy and a high risk of infections..(4,5)

For these reasons a careful risk - benefit assessment of glucocorticoid treatment is required.

\section{CASE PRESENTATION}

We present the case of a 61-year-old female, diagnosed with cardiovascular disease, hypertension, severe mixed dyslipidemia, gastroesophageal reflux disease, and arthrosis - who was referred to the endocrinologist by the neurosurgeon for thoracic back pain, with irradiation across intercostal spaces and radiological changes suggestive for spinal fractures.

The clinical examination revealed a patient in good condition, afebrile, with a round facies, without plethora, acne or seborrhea, with a height of $158 \mathrm{~cm}, 7 \mathrm{~cm}$ shorter than her young adult measured height, and a weight of $92 \mathrm{~kg}$ amounting to a BMI of $37 \mathrm{~kg} / \mathrm{m}^{2}$, corresponding to second degree obesity with a slight tendency to central disposition.

The skin was smooth, without purple stretch marks or spontaneous ecchymosis. The patient also presented a round dorsal kyphosis, muscle strength of the lower limbs was decreased - the patient used a cane, however she did not present evident muscle atrophies. Hemodynamically, the patient was stable, with a $140 / 100 \mathrm{mmHg}$ blood pressure and a pulse of 76 bpm, with no abdominal pain or other changes in intestinal transit.

It was also noted that the patient had decreased bilateral visual acuity.

Based on the anamnesis, the clinical examination, and the laboratory test results presented, the diagnosis of severe secondary osteoporosis, with multiple vertebral compressions was suspected.

In table no. 1 and no. 2 we present the results of the laboratory investigations performed, ranging from the initial examination to control visits.

\section{Table no. 1. Laboratory parameters}

\begin{tabular}{|c|c|c|c|}
\hline Parameters & Initially & Control & $\begin{array}{c}\text { Normal } \\
\text { values }\end{array}$ \\
\hline $\begin{array}{l}\text { FPG (fasting } \\
\text { plasma glucose) }\end{array}$ & $\begin{array}{c}150 \mathrm{mg} / \mathrm{dL} \text {, } \\
149.78 \mathrm{mg} / \mathrm{dL}\end{array}$ & $\begin{array}{l}106.99 \\
\mathrm{mg} / \mathrm{dL}\end{array}$ & $70-100 \mathrm{mg} / \mathrm{dl}$ \\
\hline HbA1c & - & $7 \%$ & $\leq 6 \%$ \\
\hline Total Cholesterol & $333 \mathrm{mg} / \mathrm{dL}$ & $299 \mathrm{mg} / \mathrm{dL}$ & $<200 \mathrm{mg} / \mathrm{dL}$ \\
\hline Triglycerides & $481 \mathrm{mg} / \mathrm{dL}$ & $383 \mathrm{mg} / \mathrm{dL}$ & $<150 \mathrm{mg} / \mathrm{dL}$ \\
\hline Serum Sodium & $143 \mathrm{mmol} / \mathrm{L}$ & $\begin{array}{c}138.43 \\
\mathrm{mmol} / \mathrm{L}\end{array}$ & $\begin{array}{l}132-146 \\
\mathrm{mmol} / \mathrm{L}\end{array}$ \\
\hline Serum Potassium & $4.91 \mathrm{mmol} / \mathrm{L}$ & $4.24 \mathrm{mmol} / \mathrm{L}$ & $\begin{array}{l}3.5-5.5 \\
\mathrm{mmol} / \mathrm{L}\end{array}$ \\
\hline
\end{tabular}

${ }^{1}$ Corresponding author: Ioana Codruța Lebădă, Str. Bradului, Nr. 14, Cugir, România, E-mail: roxana.inta @ulbsibiu.ro, Phone: +40 787625843 Article received on 22.04.2021 and accepted for publication on 31.05.2021 


\section{CLINICAL ASPECTS}

Table no. 2. Hormonal determinations and laboratory parameters on bone metabolism

\begin{tabular}{|c|c|c|}
\hline Parameters & Obtained values & Normal values \\
\hline Plasma Cortisol & $1.49 \mu \mathrm{g} / \mathrm{dL}$ & $6.4-21.0 \mu \mathrm{g} / \mathrm{dL}$ \\
\hline Serum Ionic Calcium & $4.32 \mathrm{mg} / \mathrm{dL}$ & $3.48-5.17 \mathrm{mg} / \mathrm{dL}$ \\
\hline Serum Total Calcium & $10.03 \mathrm{mg} / \mathrm{dL}$ & $8.7-10.4 \mathrm{mg} / \mathrm{dL}$ \\
\hline Urinary Calcium & $213 \mathrm{mg} / 24 \mathrm{~h}$ & $100-300 \mathrm{mg} / 24 \mathrm{~h}$ \\
\hline Serum Phosphorus & $3.95 \mathrm{mg} / \mathrm{dL}$ & $2.4-5.1 \mathrm{mg} / \mathrm{dL}$ \\
\hline 25-OH-Vitamin D & $14.1 \mathrm{ng} / \mathrm{mL}$ & $30-100 \mathrm{ng} / \mathrm{mL}$ \\
\hline PTH & $26.7 \mathrm{pg} / \mathrm{mL}$ & $15-65 \mathrm{pg} / \mathrm{mL}$ \\
\hline Beta crosslaps ( $\beta$-CTx $)$ & $0.49 \mathrm{ng} / \mathrm{mL}$ & $\leq 1.008 \mathrm{ng} / \mathrm{mL}$ \\
\hline Osteocalcin & $12 \mathrm{ng} / \mathrm{mL}$ & $15-46 \mathrm{ng} / \mathrm{mL}$ \\
\hline TSH & $1.94 \mu \mathrm{UI} / \mathrm{mL}$ & $0.38-5.88 \mu \mathrm{UI} / \mathrm{mL}$ \\
\hline FT4 & $0.72 \mathrm{ng} / \mathrm{dL}$ & $0.61-1.12 \mathrm{ng} / \mathrm{dL}$ \\
\hline ATPO & negative & negative \\
\hline
\end{tabular}

Starting from the suppressed cortisol level, the patient reports the fact that she self-administered oral corticosteroid medication represented by Medrol, $16 \mathrm{mg}$ twice a day, for about 1 year, treatment that has been prescribed in the past for ophthalmological reasons.

Dual-energy x-ray absorptiometry exam of the left hip shows a $\mathrm{T}$ score of $-3.3 \mathrm{SD}, \mathrm{Z}$ score of $-3 \mathrm{SD}$, with a BMD of $0.609 \mathrm{~g} / \mathrm{cm}^{2}$ and on the femoral neck a $\mathrm{T}$ score of $-2.9 \mathrm{SD}, \mathrm{Z}$ score of $-2.0 \mathrm{SD}$ and BMD of $0.695 \mathrm{~g} / \mathrm{cm}^{2}$ indicating a severe impact on the bone mineral density.

The MRI examination of the dorso-lumbar spine (which was performed by the neurosurgeon), confirmed the changes shown by the dorso-lumbar radiography, with important bone resorption at T12-L2 (nail-shaped vertebrae) and at L4-L5 (reducing the vertical axis).

Figure no. 1. Hip dexascan

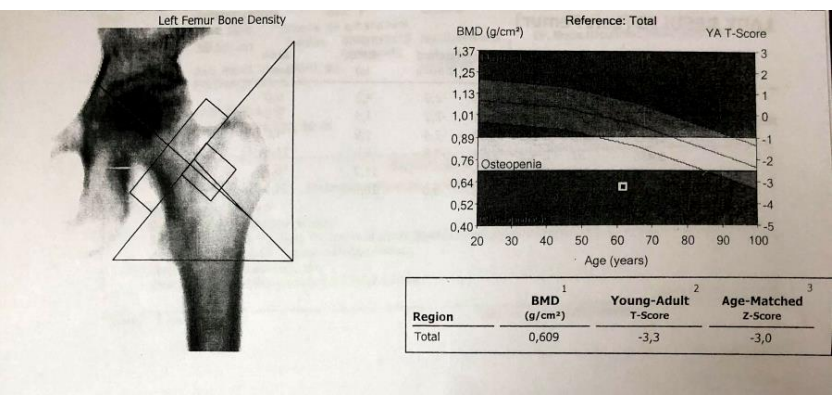

\section{LARY RESULTS [Left Femur]}

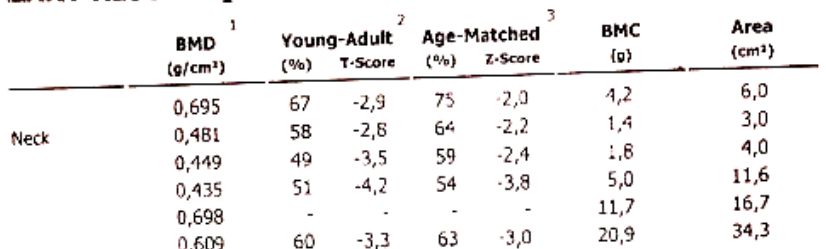

Based on clinical and paraclinical data, the following diagnoses were established: severe osteoporosis secondary to corticosteroid therapy and postmenopausal, adrenal insufficiency due to exogenous glucocorticoids, new-onset diabetes mellitus and severe mixed dyslipidemia.

The following treatment was initiated: Teriparatidum 20 $\mu \mathrm{g}$ daily, subcutaneous injection at the same time, Cholecalciferol 2000 IU per day, Calcium $1000 \mathrm{mg}$ twice daily, Omeprazole 20 $\mathrm{mg}$ once per day, Prednisone $5 \mathrm{mg}$, half a day (related to the patient's clinical status). records for evolution of the disease.

The side effects of glucocorticoids are dependent on treatment duration and dose. Depending on the intensity of the anti-inflammatory effect, its duration and the existence or absence of a mineralocorticoid effect, there are several systemic glucocorticoid agents. Medrol is an agent with intermediate action time (18-36h) that has moderate anti-inflammatory effects and is free of mineralocorticoid effects. $(1,5)$

Corticosteroids are among the most common causes of secondary osteoporosis, followed by hypogonadism, hyperparathyroidism and vitamin D deficiency. Factors such as age, the female gender, postmenopausal status, white race, a positive family history for osteoporosis, smoking, alcohol consumption, inadequate diet and a sedentary lifestyle can cause primary osteoporotic disease. $(6,7)$

Our patient has osteoporosis of multiple causes, being a postmenopausal woman, with a low estrogen status who self treated with potent steroids.

Glucocorticoids have direct effects on bone metabolism - they decrease bone formation (inhibit osteoblast activity and bone matrix synthesis) and increase bone resorption (stimulation of osteoclast synthesis), as well as indirect effects consisting on decreasing intestinal absorption and tubular calcium reabsorption. $(3,8)$

In the case of our patient, these changes were reflected by the level of bone markers, the high level of Beta crosslaps ( $\beta$ CTx) demonstrating an increasing in bone resorption, paralleled by a low level of Osteocalcin, suggestive of decreased bone formation.

The gold standard for the diagnosis of osteoporosis is the dual energy X-ray absorptiometry exam (DXA), performed either on the hip or on the lumbar spine. In the case of our patient, we opted for a hip examination because existing spinal fractures would have a negative impact on the BMD results. This diagnostic method is based on the $\mathrm{T}$ score used to interpret bone mineral density and to correlate the results with the risk of fracture. According to the World Health Organization, a T score less or equal to $-2.5 \mathrm{SD}$ indicates osteoporosis. The $\mathrm{Z}$ score is used in cases of suspected secondary osteoporosis as it compares the patient's bone mineral density within its own age and sex group. $(9,10,11)$

One way to estimate the 10-year fracture risk is the Fracture Risk Assessment Tool (FRAX) algorithm, developed by the University of Sheffield in the UK and available online. This algorithm can be used, in addition to the DXA scan, in order to help determine which patients require osteoporotic treatment. $(10,11)$

FRAX was not considered a very valuable tool in our patient is because of the existence of multiple spinal fractures.

Regarding the treatment of osteoporosis, there are multiple classes of drugs according to their effect on the bone. Thus, there are antiresorptive drugs (which reduce the rate of bone resorption, such as bisphosphonates, estrogen agonists or antagonists, calcitonin, denosumab) and anabolic agents (which promote bone formation, such as teriparatidum).(11)

Bisphosphonates inhibit osteoclast activity and thus decrease bone resorption, unfortunately their side effects such include gastroesophageal reflux disease, must be taken into account. $(8,12)$

Anabolic agents such as teriparatidum, a recombinant human parathyroid hormone analog (PTH 1-34) which has an identical sequence to the $34 \mathrm{~N}$-terminal amino acids (the biologically active region) of the 84-amino acid human parathyroid hormone, are preparations which promote bone formation by stimulating bone turn over when given in daily doses.(13)

A study by Kenneth $G$ Saag et al demonstrated the beneficial effect of teriparatidum (Forsteo) compared to alendronate (Fosamax) on increasing bone mineral density and 


\section{CLINICAL ASPECTS}

bone strength in patients with osteoporosis. The study included 428 patients- 214 received $20 \mu \mathrm{g}$ teriparatidum per day and 214 received $10 \mathrm{mg}$ alendronate per day. After 6 months of treatment, the BMD increase was higher in patients receiving teriparatidum $(7.2 \%)$ in comparison with those treated with alendronate $(3.4 \%)$. There were also less vertebral fractures $(0.6$ teriparatidum vs 6.1 alendronate) and nonvertebral fractures (5.6 teriparatidum vs 3.7 alendronate). Moreover, bone markers began to increase by $44.8 \%$ in the first month, reaching a maximum value $(69.8 \%)$ at 6 months in patients treated with teriparatidum, while patients receiving alendronate experienced a decrease in bone markers present from the first month, until the 18th month.(14)

In our case, the treatment with teriparatidum was chosen due to its stimulating effect on bone mass formation and because the patient presented with gastroesophageal reflux disease, in which case bisphosphonates are not an option. In addition, the patient received calcium and vitamin D preparations according to the current guidelines.

Long-term and high-dose therapy with glucocorticoids causes the suppression of the hypothalamic-pituitary-adrenal axis. Thus, the adrenal cortex loses its ability to produce cortisol, ACTH being low or even absent. Increased levels of exogenous glucocorticoids cause atrophy of the adrenal cortex and the appearance of tertiary adrenal insufficiency. $(2,15,16)$

Prednisone therapy was chosen due to the lack of hydrocortisone in Romania.

Treatment with corticosteroids, especially with high doses (over $30 \mathrm{mg}$ ) is associated with hyperglycemia and thus with the development of the diabetes mellitus. The incidence of hyperglycemia and diabetes mellitus in patients treated with corticosteroids (without a history of diabetes) is $32,3 \%$ and $18,36 \%$, respectively. Glucose levels were found to increase proportionally with the corticosteroid dose. The mechanisms that lead to hyperglycemia are increasing glucose production by the liver, decreasing insulin production by the pancreas and the development of peripheral insulin resistance. $(17,18)$

The medical literature describes similar cases in which complications of glucocorticoid therapy occur. For instance, a case published by Satyanarayanasetty et al in 2015 describes a 55-year-old patient, known as diabetic, who had previously been prescribed betamethasone $10 \mathrm{mg}$ tablets for 10 days for an asthma attack. The patient continued glucocorticoid therapy for 8 years and complications such as adrenal insufficiency, osteoporosis and ocular complications (subcapsular cataract) were present.(19)

Another similar case published by Khurshid HF et al in 2016 describes infectious complications in a 70-year-old patient who had self-administered prednisone and tetracycline for 10 years. The patient suffered a minor leg injury, which led to sepsis, aggravated by the induced adrenal insufficiency.(20)

\section{CONCLUSIONS}

Therefore, even if corticosteroid therapy has beneficial anti-inflammatory and analgesic effects for the patient, it is important not to use this pharmaceutical class excessively.

Moreover, patients should be educated about the selfadministration of this kind of drugs and informed about their side effects. Before corticosteroid therapy, the patient should be evaluated about the risk of complications, and an interdisciplinary physicians' collaboration is required, especially if the patient has a history of conditions that may be exacerbated by corticosteroid treatment.

\section{REFERENCES}

1. Williams DM. Clinical Pharmacology of Corticosteroids. Respir Care. 2018;63(6):655-670.
2. Alan IS, Alan B. Side Effects of Glucocorticoids. In: Malangu N, editor. Pharmacokinetics and Adverse Effects of Drugs - Mechanisms and Risks Factors. London: IntechOpen; 2017. p. 93-124.

3. Stanbury RM, Graham EM. Systemic corticosteroid therapy-side effects and their management. $\mathrm{Br} \mathrm{J}$ Ophthalmol. 1998;82(6):704-8.

4. Hougardy DM, Peterson GM, Bleasel MD, Randall CT. Is enough attention being given to the adverse effects of corticosteroid therapy. Journal of Clinical Pharmacy and Therapeutics. 2000;25(3):227-234.

5. McDougall D, Bhibhatbhan A, Toth C. Adverse effects of corticosteroid therapy in neuromuscular diseased patients are common and receive insufficient prophylaxis. Acta Neurol Scand. 2009;120(5):364-7.

6. Pouresmaeili F, Kamalidehghan B, Kamarehei M, Goh YM. A comprehensive overview on osteoporosis and its risk factors. Ther Clin Risk Manag. 2018;14(1):2029-2049.

7. Rees A, Levy M, Lansdown A. Clinical endocrinology and diabetes at a glance. 1st ed. Hoboken: Wiley; 2017.

8. Compston J. Glucocorticoid-induced osteoporosis: an update. Endocrine. 2018;61(1):7-16.

9. Sheu A, Diamond T. Bone mineral density: testing for osteoporosis. Australian prescriber. 2016;39(2):35-39.

10. WHO Scientific Group on the assessment of osteoporosis at primary health care level. Summary meeting report. Brussels: World Health Organization.; 2004. p.1-17.

11. Tu KN, Lie JD, Wan CKV, Cameron M, Austel AG, Nguyen JK, Van K, Hyun D. Osteoporosis: A Review of Treatment Options. P T. 2018;43(2):92-104.

12. Peng YL, Hu HY, Luo JC, Hou MC, Lin HC, Lee FY. Alendronate, a bisphosphonate, increased upper and lower gastrointestinal bleeding: risk factor analysis from a nationwide population-based study. Osteoporos Int. 2014;25(5):1617-23.

13. Lindsay R, Krege JH, Marin F, Jin L, Stepan JJ. Teriparatide for osteoporosis: importance of the full course. Osteoporos Int. 2016;27(8):2395-410.

14. Saag KG, Shane E, Boonen S, Marín F, Donley DW, Taylor KA, Dalsky GP, Marcus R. Teriparatide or alendronate in glucocorticoid-induced osteoporosis. N Engl J Med. 2007;357(20):2028-39.

15. Joseph RM, Hunter AL, Ray DW, Dixon WG. Systemic glucocorticoid therapy and adrenal insufficiency in adults: A systematic review. Semin Arthritis Rheum. 2016;46(1):133-41.

16. Ospina NS, Al Nofal A, Bancos I, Javed A, Benkhadra K, Kapoor E, Lteif AN, Natt N, Murad MH. ACTH Stimulation Tests for the Diagnosis of Adrenal Insufficiency: Systematic Review and Meta-Analysis. J Clin Endocrinol Metab. 2016 Fe;101(2):427-34.

17. Morris D. Steroid-induced diabetes and hyperglycaemia. Part 1: mechanisms and risks. Diabetes \& Primary Care. 2018;20(4):151-3.

18. Ginzler EM, Aranow C. 7 Prevention and treatment of adverse effects of corticosteroids in systemic lupus erythematosus. Baillière's Clinical Rheumatology. 1998;12(3):495-510.

19. Satyanarayanasetty D, Pawar K, Nadig P, Haran A. Multiple Adverse Effects of Systemic Corticosteroids: A Case Report. J Clin Diagn Res. 2015;9(5):FD01-2.

20. Khurshid HF, Zikria S, Hamid S, Kumar VA. SelfMedication of Corticosteroids: A Life Threatening Case Report from Pakistan. Journal of Pharmacy Practice and Community Medicine. 2016;2(3):96-9. 